\title{
Patterns of dental caries among school children assessed using Caries Assessment Spectrum and Treatment tool
}

\author{
Hisham El Batawi ${ }^{1}$, Kausar Sadia Fakhruddin ${ }^{1}$
}

Correspondence: Dr. Hisham El Batawi

Email: helbatawi@sharjah.ac.ae
'Department of Preventive and Restorative Dentistry, College of Dental Medicine, University of Sharjah, United Arab Emirates

\section{ABSTRACT}

Objective: The present study aimed to assess and monitor patterns of dental caries among primary and permanent molars using Caries Assessment Spectrum and Treatment (CAST) index and to evaluate integration of CAST tool into patient health information (PHI) system of a Teaching Dental Hospital. Materials and Methods: Dental records of $n=348$ children, aged 7-9-years, attending University Dental Hospital Sharjah, for routine checkup and treatment as part of School Dental Program were assessed and translated into CAST codes. Dental caries prevalence for the second primary and first permanent molars were recorded. Spearman's correlation coefficient was used to assess the correlation of the status between primary and permanent molar. Results: CAST codes $0-2$ were observed only in about $3 \%$ of primary and almost $5 \%$ in permanent dentition. The prevalence of children with diseased first permanent molar (codes 4-7) was almost $67 \%$, while it was over $70 \%$ in second primary molars. A strong correlations were observed in the status between second primary and first permanent molars in the lower jaw on both right and left sides, $r$ was 0.694 and $0.643(P=0.001)$, respectively. In the upper jaw, both right and left second primary molars revealed moderate correlation $r=0.435(P \leq 0.05)$ between disease stages with their neighboring permanent first molars. The unweighted kappa value for the intraexaminer reliability was 0.97 for second primary and 0.95 for first permanent molars. Conclusion: Our study recommends the integration of CAST tool in the PHI system where a simple numerical value can express clinical progress, overcome interruptions of treatment, and ensures continuity of patient care in teaching hospitals.

Key words: Assessment, caries, Caries Assessment Spectrum and Treatment, index, permanent, primary, teeth

\section{INTRODUCTION}

Dental caries remains a major public health problem on the community level and continues to be a source of pain, suffering and low quality of life on an individual level. ${ }^{[1,2]}$ The dynamic nature of the disease manifests it in different shapes, depths, sizes, and colors of lesions which is reflected on the wide spectrum of different strategies available to control it ranging from remineralization, fluoride application, atraumatic restorative treatment to

\begin{tabular}{|l|l|}
\hline \multicolumn{2}{|c|}{ Access this article online } \\
\hline Quick Response Code: \\
\hline
\end{tabular}

extensive cavity preparation, pulp therapy, and full coverage. ${ }^{[3,4]}$

To help dental practitioners and dental program planners develop effective caries control measures, many tools for the assessment of dental caries have been presented. Among these, the most widely used was the decayed, missing and filled teeth index (DMFT), recommended by the World Health

This is an open access article distributed under the terms of the Creative Commons Attribution-NonCommercial-ShareAlike 3.0 License, which allows others to remix, tweak, and build upon the work non-commercially, as long as the author is credited and the new creations are licensed under the identical terms.

For reprints contact: reprints@medknow.com

How to cite this article: El Batawi H, Fakhruddin KS. Patterns of dental caries among school children assessed using Caries Assessment Spectrum and Treatment tool. Eur J Dent 2017;11:168-73.

DOI: 10.4103/ejd.ejd_120_17 
Organization (WHO). Even though the index had its strengths, yet the D-component showed a wide range of variation. The need to monitor and assess the severity of the D-component of the DMFT index in recent decades was the main reason for researchers to develop the International Caries Detection and Assessment System (ICDAS). ${ }^{[4,5]}$ The ICDAS system had an advantage of helping to distinguish three stages of caries severity in enamel, but it required complete dryness of the tooth surface using dry air and double checking which rendered surveys to be time and money consuming. ${ }^{[6]}$ Later, two indices were developed to assess the severe course of untreated dental caries, the Pulpal Involvement-Ulceration-Fistula-Abscess and the Pulpal Involvement-Roots-Sepsis but their disadvantage is that they do cover a limited area of the wide range of caries process letting them act complementary to DMFT and ICDAS. From the clinical perspective as well as the epidemiological point of view, it is always advantageous to implement a single simple index to monitor the whole spectrum of a disease. ${ }^{[7]}$

In 2011, Frencken et al. ${ }^{[3]}$ developed the Caries Assessment Spectrum and Treatment (CAST) index. An advantage of CAST is that it counts successfully restored teeth as sound teeth which is an epidemiologically acceptable concept of health. It covers also the whole spectrum of dental caries starting from sound, preventive, restorative, to caries in enamel and dentin, reaching to the advanced stages of untreated lesions of pulpal involvement and surrounding tooth structures up to eventual tooth loss. CAST codes follow a hierarchical manner describing the increased caries severity and additionally contain all the WHO caries assessment criteria; it eliminates the need for drying the tooth surface making it a straightforward, practical and easy to implement system.

Through the years, the hypothesis that teeth get decayed in a random manner was rejected. It is observed that dental caries follows some universal patterns, for example, symmetrical distribution around the midline as well as between upper and lower jaws. In 2004, Batchelor and Sheiham ${ }^{[8]}$ demonstrated that a true symmetry of dental caries does not exist, but there are certain groups of teeth that share the same caries susceptibility.

Most of the literature on patterned dental caries adopted the DMF and DMFT indices. Recently, the ICDAS tool was used to assess the patterned occurrence of dental caries. However as CAST is gaining more acceptances worldwide, it might have a potential to be a useful tool for planning caries control programs on both individual and community levels.

The aim of this study is to demonstrate the use of CAST tool in monitoring patterns of dental caries among primary and permanent molars and to evaluate integrating the tool into the patient health information (PHI) system of a teaching dental hospital.

\section{MATERIALS AND METHODS}

Dental records of 348 children, aged 7-9 years $(n=167$ boys, and $n=181$ girls) attending University Dental Hospital Sharjah (UDHS) from February to December 2016 for routine checkup and treatment as part of a school dental program arranged by the University of Sharjah, United Arab Emirates.

After obtaining parents or caregivers approval according to the institution's policy, charting was done on the hospital's PHI system (axiUm ${ }^{\circledR}$ Exan division of Henry Schein Co.). Dental examination and data entry into axiUm ${ }^{\circledR}$ was done by students on patients seated on dental chairs under supervision of pediatric dentist faculty members using plane mirrors and sharp explorers. Routine orthopantomogram was taken and stored into another separate computer software module other than/axiUm ${ }^{\circledR}$.

On time/while the study was conducted, axiUm ${ }^{\circledR}$ records were examined retrospectively where both pre- and post-treatment health status for each individual tooth was translated into CAST codes.

To achieve a reliable translation to CAST codes, every clinical side note, as well as every pretreatment panoramic radiograph, was examined by two pediatric dentists who had to agree on the designated code for each tooth. The unweighted kappa value for the interexaminer reliability was 0.97 for second primary and 0.95 for first permanent molars. The same two pediatric dentists performed the translation to CAST for all the records included in the study. If two conditions were present on the same tooth or tooth surface, the condition with the higher score was counted. All the children's records included in the study had four first permanent molars erupted. We excluded records with any of the premolars erupted to avoid confusion related to whether the primary molar was lost due to caries or was normally exfoliated. 
For the purpose of our study, CAST codes 1, 2 were considered healthy, 3 were considered as premorbid, 4-7 for morbidity, and 8 for mortality. CAST codes for primary and permanent molars were tabulated and recorded for statistical analysis. For statistical analysis, the nonparametric Mann-Whitney U-test was used to test the difference in the distribution of CAST codes in evaluated second primary molar and first permanent molar according to age and gender. Spearman's Correlation Coefficient was used to assess the correlation between caries status of second primary molar and permanent first molars. The statistical significance was set at 0.05.

\section{RESULTS}

Dental records of a total of $n=348$ children, aged between 7 and 9-years ( $n=167$ boys, and $n=181$, girls) were examined in this study. The recorded dental status of the second primary and first permanent molars were evaluated and translated into CAST codes. Table 1 represents the distribution of each CAST code separately for evaluated primary and permanent molars.

Based on the epidemiological concept of health and disease, proposed by Frencken et al., ${ }^{[4]}$ healthy dentition status is represented by codes $0-2$. In our study, CAST codes $0-2$ were observed only in about $3 \%$ primary and almost $5 \%$ in permanent dentition, respectively. The prevalence of children with diseased first permanent molar is almost $67 \%$ (codes $4-7$ ). While in second primary molars, the recorded prevalence is over $70 \%$ for representing teeth with morbidity and severe morbidity.

With regards to second primary molars, over one-third of the teeth had pulpal involvement (code 6-serious morbidity). Caries in first permanent molars was mostly evaluated and recoded as the dentinal lesions, with morbidity codes 4 (discolored dentin visible through enamel, with or without enamel breakdown) or code 5 (distinct cavitation into dentine), with the prevalence of over $50 \%$. Tooth extracted due to caries (code 8), was found to be more prevalent (almost $10 \%$ ) in primary molars versus $1 \%$ in first permanent molar, represented in Figure 1.

A strong correlation was found between caries stages of lower right and neighboring first permanent molars $r=0.69$, and lower left second primary and permanent dentition $r=0.64$ Figures 2 and 3. All the correlations between primary and permanent molars in the lower jaw reached high statistical significance $(P=0.001)$. With regard to the teeth in the upper arch, both right and left second primary molar revealed moderate correlation $r=0.435(P \leq 0.05)$, between disease stages with their neighboring permanent first molars, Figures 4 and 5 .

Table 2 demonstrates the hierarchical structure in CAST codes which follows severity of the consequences of disease stages, with increasing codes before provision of treatment. Following caries treatment, a restored tooth is considered functional and healthy and therefore, these codes were changed from diseased to healthy status. Moreover, as many as $16.5 \%$ of lower first permanent molar were lost due to extraction, while only an average of $2.9 \%$ could have been saved after endodontic treatment for teeth categorized as code 6 or 7 .

\section{DISCUSSION}

Dental caries is a major oral health problem worldwide. $\mathrm{WHO}, 2005$ bulletin reports caries the prevalence of $60 \%-90 \%$ among school-aged children and the vast majority of adults in the majority of countries. ${ }^{[9]}$ In this study, a high prevalence of carious first permanent molars in over $65 \%$ of children was observed, which is in agreement with the previously reported data from a Saudi study among children aged-9-12-years. ${ }^{[10]}$

Several studies ${ }^{[11-13]}$ documented that dental caries in deciduous dentition is a strong predictive factor of

\begin{tabular}{|c|c|c|c|c|c|c|c|c|c|}
\hline Tooth No & Code 0 & Code 1 & Code 2 & Code 3 & Code 4 & Code 5 & Code 6 & Code 7 & Code 8 \\
\hline 16 & 1.7 & 1.1 & 9.2 & 18.2 & 21.8 & 30.7 & 12.1 & 2.6 & 2.6 \\
\hline 26 & 1.8 & 1.2 & 9.5 & 17.1 & 21.3 & 31.3 & 12.4 & 4.3 & 1.1 \\
\hline 36 & 2.5 & 3.6 & 7.3 & 21.2 & 17.3 & 27.1 & 19.2 & 1.6 & 0.2 \\
\hline 46 & 2.3 & 0.7 & 10.8 & 20.5 & 19.8 & 26.7 & 17.6 & 1.2 & 0.4 \\
\hline 55 & 1.3 & 0 & 5.6 & 8.6 & 8.3 & 21.4 & 40.6 & 4.1 & 10.1 \\
\hline 65 & 1.5 & 0 & 5.1 & 7.5 & 8.3 & 22.1 & 42 & 3.8 & 9.7 \\
\hline 75 & 0.8 & 0 & 4 & 10.3 & 8.9 & 21.6 & 37.2 & 8.2 & 9 \\
\hline 85 & 2.5 & 0 & 6.3 & 15.8 & 7.3 & 22.1 & 26.7 & 9.1 & 10.2 \\
\hline
\end{tabular}




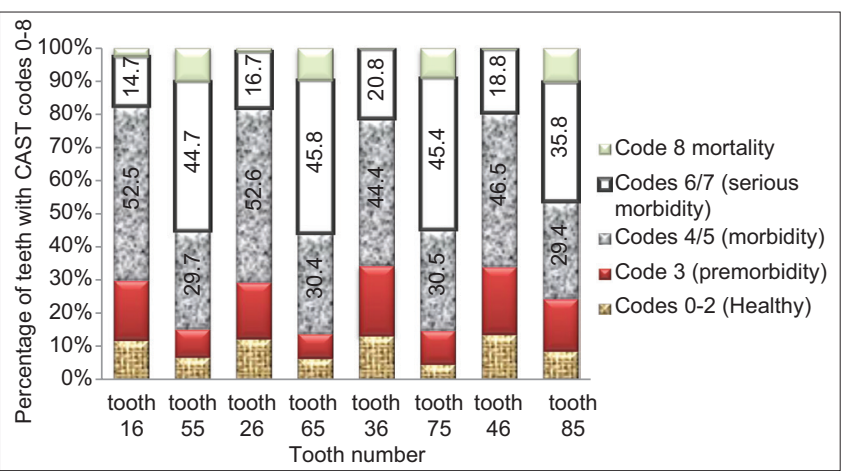

Figure 1: Distribution of evaluated second primary and first permanent molar teeth according to the concept of health and different disease stages

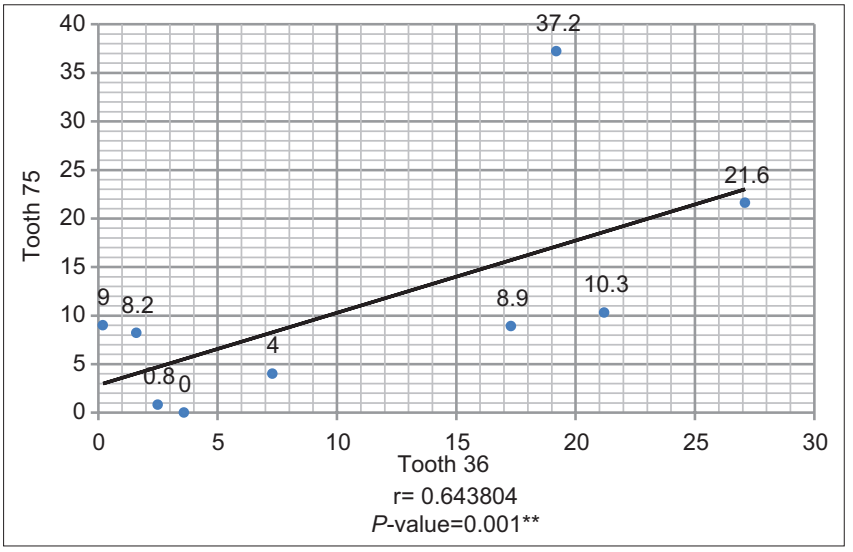

Figure 3: Correlation of Caries Assessment Spectrum and Treatment codes between tooth 36 and 75

a high caries increment in the permanent dentition, especially in the first permanent molars. Neglect in dental care related to deciduous dentition is obvious with the prevalence of over $70 \%$ for codes 4-7 representing teeth with morbidity and severe morbidity. This could be strongly correlated to high caries prevalence in first permanent molars, as observed in this study. Mandatory dental screenings should be initiated at the age of 5 years, and periodic follow-ups for another 5-6 years. This will help identify children with high caries risk and for the provision of preventive care such as dental sealants to high-risk group. Results from the present study indicated an extremely low percentage of pit and fissure sealants in the permanent teeth and negligible in the primary molars. Considering number of factors such as age, early eruption, anatomy, large crown size, position in the oral cavity, and makes first permanent molars highly susceptible to caries. ${ }^{[14,15]}$ Sealants are strongly recommended for susceptible tooth surfaces in high-risk population employing appropriate material and technique. ${ }^{[16,17]}$

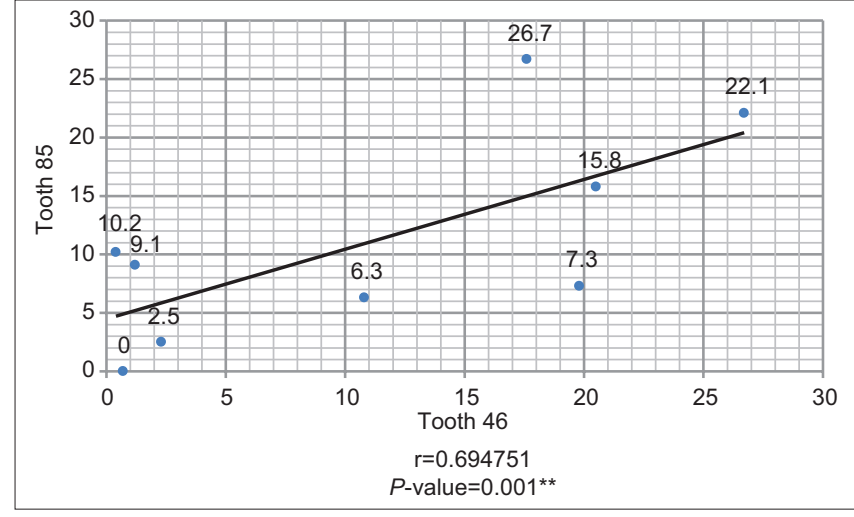

Figure 2: Correlation of Caries Assessment Spectrum and Treatment codes between tooth 46 and 85

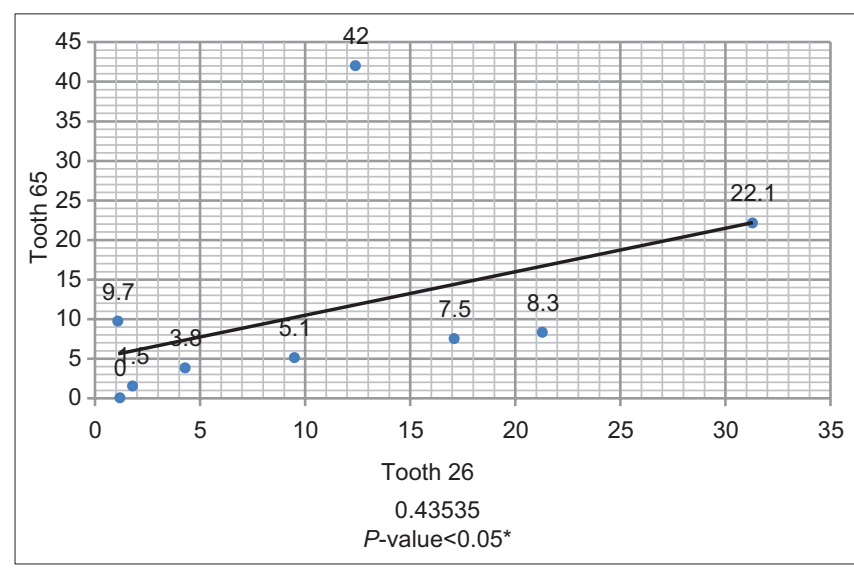

Figure 4: Correlation of Caries Assessment Spectrum and Treatment codes between tooth 26 and 65

At UDHS, we follow comprehensive care in our undergraduate and postgraduates-teaching clinics. Using radiographic records retrieved from PHI system $\left(\right.$ axiUm $\left.^{\circledR}\right)$ we translated different disease stages of caries into CAST morbidity codes (codes 4-7). Formulated treatment plan for comprehensive care entered in the system was based on the diagnosis explaining caries types (primary caries, arrested caries), etc., only. It was quite tedious for us to relate radiographic records, clinical notes supporting the diagnosis, treatment plan and treatment rendered especially for caries involving enamel and dentine with no pulpal involvement. Documentation in clinical notes of the stages of carious lesions both for early and for more severe levels using caries assessment criteria is necessary for learning and periodic follow-up of the high-risk patients.

Among many systems, the CAST instrument is a promising tool which gives a full spectrum of the clinical picture of dental caries from enamel and dentine carious lesions to advanced stages of 


\begin{tabular}{|c|c|c|c|c|c|}
\hline $\begin{array}{l}\text { Tooth No. } \\
\text { CAST Codes }\end{array}$ & $\begin{array}{l}\text { Status of teeth } \\
\text { acc. to CAST } \\
\text { codes }\end{array}$ & $\begin{array}{l}\text { Percentage distribution } \\
\text { of teeth acc. to CAST } \\
\text { codes before treatment }\end{array}$ & $\begin{array}{l}\text { Type of Treatment } \\
\text { provided }\end{array}$ & $\begin{array}{l}\text { CAST } \\
\text { codes after } \\
\text { treatment }\end{array}$ & $\begin{array}{l}\text { Status and Percentage } \\
\text { distribution of teeth acc. to } \\
\text { CAST codes after treatment }\end{array}$ \\
\hline \multicolumn{6}{|l|}{ Tooth No. 16} \\
\hline Code 3 & Pre-morbidity & 18.2 & $\begin{array}{l}\text { Sealant/PRR/ } \\
\text { Restorative care }\end{array}$ & $3 \rightarrow 1$ or 2 & Healthy (18.2) \\
\hline Code $4 / 5$ & Morbidity & 52.5 & Restorative care/IPT & $4 / 5 \rightarrow 2$ & Healthy (52.5) \\
\hline Code 6 & Morbidity & 12.1 & $\begin{array}{l}\text { Pulp treatment/ } \\
\text { Extraction }\end{array}$ & $6 \rightarrow 2$ or 8 & Healthy (2.3) \& \\
\hline Code 7 & Morbidity & 2.6 & Extraction & $7 \rightarrow 8$ & Mortality (9.8) \\
\hline Code 8 & Mortality & 2.6 & & & Mortality (2.6) \\
\hline \multicolumn{6}{|l|}{ Tooth No. 26} \\
\hline Code 3 & Pre-morbidity & 17.1 & $\begin{array}{l}\text { Sealant/PRR/ } \\
\text { Restorative care }\end{array}$ & $3 \rightarrow 1$ or 2 & Healthy (17.1) \\
\hline Code $4 / 5$ & Morbidity & 52.6 & Restorative care/IPT & $4 / 5 \rightarrow 2$ & Healthy (52.6) \\
\hline Code 6 & Morbidity & 12.4 & $\begin{array}{l}\text { Pulp treatment/ } \\
\text { Extraction }\end{array}$ & $6 \rightarrow 2$ or 8 & Healthy (2.7) \\
\hline Code 7 & Morbidity & 4.3 & Extraction & $7 \rightarrow 8$ & Mortality (9.7) \\
\hline Code 8 & Mortality & 1.1 & & & Mortality (4.3) \\
\hline \multicolumn{6}{|l|}{ Tooth No. 36} \\
\hline Code 3 & Pre-morbidity & 21.2 & $\begin{array}{l}\text { Sealant/PRR/ } \\
\text { Restorative care }\end{array}$ & $3 \rightarrow 1$ or 2 & Healthy (21.2) \\
\hline Code $4 / 5$ & Morbidity & 44.4 & Restorative care/IPT & $4 / 5 \rightarrow 2$ & Healthy (44.4) \\
\hline Code 6 & Morbidity & 19.2 & $\begin{array}{l}\text { Pulp treatment/ } \\
\text { Extraction }\end{array}$ & $6 \rightarrow 2$ or 8 & Healthy (5.2) \\
\hline Code 7 & Morbidity & 1.6 & Extraction & $7 \rightarrow 8$ & Mortality (14) \\
\hline Code 8 & Mortality & 0.2 & & & Mortality (1.6) \\
\hline \multicolumn{6}{|l|}{ Tooth No. 46} \\
\hline Code 3 & Pre-morbidity & 20.5 & $\begin{array}{l}\text { Sealant/PRR/ } \\
\text { Restorative care }\end{array}$ & $3 \rightarrow 1$ or 2 & Healthy (20.5) \\
\hline Code $4 / 5$ & Morbidity & 46.5 & Restorative care/IPT & $4 / 5 \rightarrow 2$ & Healthy (46.5) \\
\hline Code 6 & Morbidity & 17.6 & $\begin{array}{l}\text { Pulp treatment/ } \\
\text { Extraction }\end{array}$ & $6 \rightarrow 2$ or 8 & Healthy (1.4) \\
\hline Code 7 & Morbidity & 1.2 & Extraction & $7 \rightarrow 8$ & Mortality (16.2) \\
\hline Code 8 & Mortality & 0.4 & & & Mortality (1.2) \\
\hline
\end{tabular}

caries, involving pulp, and surrounding tissue..$^{[4,7,18]}$ Utilizing/employing the CAST tool, a simple numerical value can reflect/reflects the precise stage of caries evaluated clinically or through radiographs which can easily be documented in the clinical notes of the patient. This can bridge any gaps in the existing PHI system. It will then become easier for future caregivers to have complete picture of the progression of caries stages for the follow-up patients.

This caries assessment tool might provide undergraduates with a structural guidance to formulate and document an effective treatment plan for comprehensive care in the PHI system. Undergraduates can have better understanding of assessing and documenting the presentation of premorbidity stage with a numerical value that only needs preventive care. Furthermore, codes 4/5 can help them distinguish carious lesion in dentine, which either can be restored or require more complicated treatment beyond restoration.

Moreover, through a comprehensive assessment of the disease stages, it may give an insight into the consequences of untreated caries. In addition, based on the assessed health, premorbid and morbid status of the tooth, students can properly select treatment modalities that can effectively change the health status from morbid to health using CAST tool.

So far, this is the first work/study where CAST tool is used on retrospective patient records. Despite this fact, the results are in agreement with other studies done by Baginska et al., ${ }^{[7]}$ where CAST tool was used during the actual clinical examination. This agreement reflects the strength and reliability of CAST as an epidemiological and clinical assessment tool. 


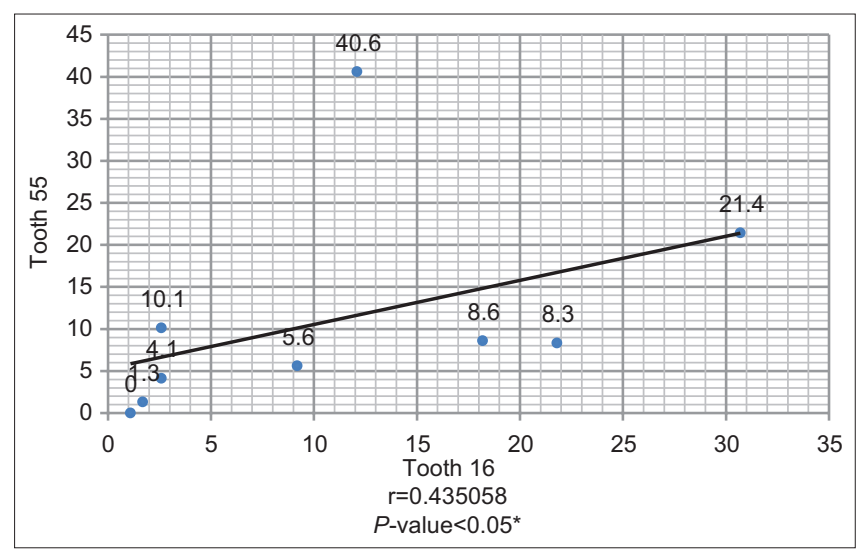

Figure 5: Correlation of Caries Assessment Spectrum and Treatment codes between tooth 16 and 55

In a teaching hospital as UDHS, it is very common that service providers (the undergraduate dental students) do alternate during provision of a certain services especially when the service requires multiple visits. This is sometimes inevitable due to events related to the learning environment, for example, graduation of students and study breaks. Our study recommends the integration of CAST tool in the PHI system where a simple numerical value can express clinical progress, overcome interruptions of treatment, and ensures continuity of patient care.

\section{CONCLUSION}

CAST tool is a valuable caries index that expresses the severity of caries and the clinical progress and outcome of management. our study recommends the integration of CAST tool in the patient health information system where a simple numerical value can express clinical progress, overcome interruptions of treatment and ensures continuity of patient care in teaching hospitals

\section{Financial support and sponsorship} Nil.

\section{Conflicts of interest}

There are no conflicts of interest.

\section{REFERENCES}

1. Burt BA, Baelum V, Fejerskov O. Dental Caries: The Disease and its Clinical Management. $2^{\text {nd }}$ ed. Frederiksberg: Blackwell Munksgaard 2008. p. 123-46.

2. de Souza AL, van der Sanden WJ, Leal SC, Frencken JE. The Caries Assessment Spectrum and Treatment (CAST) index: Face and content validation. Int Dent J 2012;62:270-6.

3. Frencken JE, de Amorim RG, Faber J, Leal SC. The Caries Assessment Spectrum and Treatment (CAST) index: Rational and development. Int Dent J 2011;61:117-23.

4. Frencken JE, de Souza AL, van der Sanden WJ, Bronkhorst EM, Leal SC. The Caries Assessment and Treatment (CAST) instrument. Community Dent Oral Epidemiol 2013;41:e71-7.

5. Pitts N. "ICDAS" - An international system for caries detection and assessment being developed to facilitate caries epidemiology, research and appropriate clinical management. Community Dent Health 2004;21:193-8.

6. Pitts NB, Ekstrand KR; ICDAS Foundation. International Caries Detection and Assessment System (ICDAS) and its International Caries Classification and Management System (ICCMS) - Methods for staging of the caries process and enabling dentists to manage caries. Community Dent Oral Epidemiol 2013;41:e41-52.

7. Baginska J, Rodakowska E, Milewski R, Kierklo A. Dental caries in primary and permanent molars in 7-8-year-old schoolchildren evaluated with Caries Assessment Spectrum and Treatment (CAST) index. BMC Oral Health 2014;14:74.

8. Batchelor PA, Sheiham A. Grouping of tooth surfaces by susceptibility to caries: A study in 5-16 year-old children. BMC Oral Health 2004;4:2.

9. Petersen PE, Bourgeois D, Ogawa H, Estupinan-Day S, Ndiaye C. The global burden of oral diseases and risks to oral health. Bull World Health Organ 2005;83:661-9.

10. Al-Samadani KH, Ahmad MS. Prevalence of first permanent molar caries in and its relationship to the dental knowledge of 9-12-year olds from Jeddah, Kingdom of Saudi Arabia. ISRN Dent 2012;2012:391068.

11. Skeie MS, Raadal M, Strand GV, Espelid I. The relationship between caries in the primary dentition at 5 years of age and permanent dentition at 10 years of age $-\mathrm{A}$ longitudinal study. Int J Paediatr Dent 2006;16:152-60.

12. Steiner M, Helfenstein U, Marthaler TM. Dental predictors of high caries increment in children. J Dent Res 1992;71:1926-33.

13. Gray MM, Marchment MD, Anderson RJ. The relationship between caries experience in the deciduous molars at 5 years and in first permanent molars of the same child at 7 years. Community Dent Health 1991;8:3-7.

14. Noronha JC, Massara Mde L, Souki BQ, Nogueira AP. First permanent molar: First indicator of dental caries activity in initial mixed dentition. Braz Dent J 1999;10:99-104.

15. Wyne AH. The bilateral occurrence of dental caries among 12-13 and 15-19 year old school children. J Contemp Dent Pract 2004;5:42-52.

16. Courson F, Velly AM, Droz D, Lupi-Pégurier L, Muller-Bolla M. Clinical decision on pit and fissure sealing according to the occlusal morphology. A descriptive study. Eur J Paediatr Dent 2011;12:43-9.

17. Berger S, Goddon I, Chen CM, Senkel H, Hickel R, Stösser L, et al. Are pit and fissure sealants needed in children with a higher caries risk? Clin Oral Investig 2010;14:613-20.

18. de Souza AL, Leal SC, Bronkhorst EM, Frencken JE. Assessing caries status according to the CAST instrument and WHO criterion in epidemiological studies. BMC Oral Health 2014;14:119. 